\title{
DIÁlOgO ENTRE LA CORTE INTERAMERICANA DE DERECHOS HUMANOS Y EL TRIBUNAL EUROPEO DE DERECHOS HUMANOS \\ A PROPÓSITO DE LAS LEYES DE AMNISTÍA
}

\section{Yennesit PALACIOS VAlencia}

Artículo de reflexión

DOI: http://dx.doi.org/10.15425/redepub.35.2015.06

Universidad de los Andes

Facultad de Derecho

Rev. derecho publico No.35

julio - diciembre de 2015. ISSN 1909-7778 


\title{
Diálogo entre la Corte Interamericana de Derechos Humanos y el Tribunal Europeo de Derechos Humanos. A propósito de las leyes de amnistía
}

\section{Resumen}

Existe un consenso firme respecto a la línea jurisprudencial desarrollada por la Corte Interamericana de Derechos Humanos (Corte IDH) y el Tribunal Europeo de Derechos Humanos (TEDH) -aunque no tanto-, en relación con la incompatibilidad de las leyes de amnistía y otras medidas con la efectiva protección de los derechos humanos, precisamente por alejarse de criterios de justicia con el establecimiento de excluyentes de responsabilidad que permiten abiertamente la impunidad. Por ello los estándares internacionales en la materia permitirán concluir que será nula de manera absoluta cualquier medida que impida la obligación de los Estados de investigar, procesar y sancionar a los autores de crímenes graves de trascendencia internacional por contravenir derechos inderogables reconocidos por el derecho internacional de los derechos humanos. Pretensión que busca que los Estados cumplan con su deber en el ejercicio de una recta aplicación de justicia.

Palabras clave: Corte Interamericana de Derechos Humanos, crímenes internacionales, derechos humanos, leyes de amnistía, Tribunal Europeo de Derechos Humanos.

\section{A dialogue between the inter-american court of human rights and the european court of human rights. With regard to amnesty laws}

\begin{abstract}
A strong, but limited consensus exists regarding Inter-American Court of Human Rights (IACHR) and the European Court of Human Rights (ECHR) jurisprudence on the incompatibility of amnesty laws and other measures involving the effective protection of human rights that move away from the principles of justice by establishing exemptions from responsibility and openly allow for impunity.

Therefore, international standards in this area support the conclusion that any measure which prevents the obligation of States to investigate, prosecute and punish perpetrators of serious international crimes that contravene non-derogable rights recognized by international human rights law shall be declared null and void. Such a claim asks that States to fulfill their duty in carrying out a direct application of justice.
\end{abstract}

Keywords: Inter-American Court of Human Rights, international crimes, human rights, amnesty laws, European Court of Human Rights.

\section{Diálogo entre a Corte Interamericana de Direitos Humanos e o Tribunal Europeu de Direitos Humanos. A propósito das leis de anistia}

\section{Resumo}

Existe um consenso firme com respeito à linha jurisprudencial desenvolvida pela Corte Interamericana de Direitos Humanos (Corte IDH) e o Tribunal Europeu de Direitos Humanos (TEDH) -embora nem tanto-, em relação com a incompatibilidade das leis de anistia e outras medidas com a efetiva proteção dos direitos humanos, precisamente por afastarse de critérios de justiça com o estabelecimento de excludentes de responsabilidade que permitem abertamente a impunidade. Por isso, os padrões internacionais na matéria permitirão concluir que será nula de maneira absoluta qualquer medida que impeça a obrigação dos Estados de investigar, processar e sancionar os autores de crimes graves de transcendência internacional por contravir direitos inderrogáveis reconhecidos pelo direito internacional dos direitos humanos. Pretensão que busca que os Estados cumpram com seu dever no exercício de uma reta aplicação de justiça.

Palavras-chave: Corte Interamericana de Direitos Humanos, crimes internacionais, direitos humanos, leis de anistia, Tribunal Europeu de Direitos Humanos. 


\title{
Diálogo entre la Corte Interamericana de Derechos Humanos y el Tribunal Europeo de Derechos Humanos A propósito de las leyes de amnistía*
}

\author{
Yennesit Palacios Valencia ${ }^{* *}$
}

\section{SUMARIO}

Introducción - I. LA CORTE INTERAMERICANA DE DERECHOS HUMANOS Y EL TRIBUNAL EUROPEO DE DERECHOS HUMANOS EN RELACIÓN CON LAS LEYES DE AMNISTÍA - A. Incompatibilidad de las leyes de amnistía con la efectiva protección de los derechos humanos - B. Impunidad en ausencia de justicia por las leyes de amnistía - II. ESTÁNDARES INTERNACIONALES SOBRE LAS LEYES DE AMNISTÍA - III. REFLEXIONES FINALES - Referencias.

* Cómo citar este artículo: Palacios Valencia, J. (Diciembre, 2015). Diálogo entre la Corte Interamericana de Derechos Humanos y el Tribunal Europeo de Derechos Humanos. A propósito de las leyes de amnistía. Revista de Derecho Público, 35. Universidad de los Andes (Colombia).

** PhD en Derechos Humanos y Desarrollo de la Universidad Pablo de Olavide de Sevilla. Abogada de la Universidad de San Buenaventura seccional Medellín; especialista en Cultura Política y Derechos Humanos de la Universidad Autónoma Latinoamericana de Medellín. Magíster en Derechos Humanos, Interculturalidad y Desarrollo de la Universidad Pablo de Olavide; Magíster en Relaciones Internacionales de la Universidad Internacional de Andalucía y Magíster en Derecho Constitucional del Centro de Estudios Políticos y Constitucionales de Madrid, adscrito al Ministerio de la Presidencia de España. Actualmente es docente - investigadora de la Maestría en Educación y Derechos Humanos de la Universidad Autónoma Latinoamericana de Medellín. Correo: yennesit.palacios@gmail.com 
Introducción

Las leyes de amnistía, por tendencia, suelen estar asociadas a la comisión de crímenes de trascendencia internacional con ocasión de la grave violación de derechos humanos que, por antonomasia, han sido producto de sistemas represivos. En el caso que nos convoca, los estándares internacionales en la materia han determinado la tajante incompatibilidad entre aquellas y los derechos humanos, pues soportan la vía a la impunidad por el distanciamiento entre los derechos de las víctimas a la verdad, justicia y reparación.

Si bien en diversos casos las transiciones democráticas que se han suscitado tanto en el continente americano como en el europeo han llevado aparejada la creación de leyes de amnistía, esto no revierte la carga de los Estados de investigar y sancionar crímenes cometidos en el pasado, idea que es una regla básica del derecho internacional concretada en norma de jus cogens; base jurídica que establece: “bajo el derecho internacional, tanto convencional como consuetudinario, los Estados tienen la obligación de juzgar y castigar por medio de sus jurisdicciones penales nacionales a los autores de graves violaciones de derechos humanos constitutivas de crímenes de derecho internacional" (Andreu-Guzmán, 2012, pág. 7).

Sin embargo, tal cometido, que es de obligatoria observancia, no es acatado en diversos escenarios, con lo cual los sistemas internacionales de protección de derechos humanos constituidos con posterioridad a la Segunda Guerra Mundial vienen diseñando y reconstruyendo de manera firme dicha fórmula, justamente para que los Estados creen medidas legales y procedimentales que propendan por una recta aplicación de justicia cuando se trate de graves violaciones a los derechos humanos e infracciones al derecho internacional humanitario.

Al respecto, la Corte Interamericana de Derechos Humanos (Corte IDH) y el Tribunal Europeo de Derechos Humanos (TEDH), también denominado Tribunal de Estrasburgo, -aunque no tanto- han marcado una amplia línea jurisprudencial sobre la incompatibilidad de las leyes de amnistía con la defensa de los derechos humanos. Así pues, este trabajo se construye bajo los estándares internacionales en la materia, esencialmente para reflexionar y resaltar los hallazgos más relevantes en la lucha contra la impunidad, en la pretensión de impulsar la tutela efectiva de los derechos humanos.

Para tal cometido, la metodología de trabajo parte esencialmente de un rastreo jurisprudencial de algunas decisiones importantes de la Corte IDH y del TEDH, para finalmente concluir que la base jurídica que ampara la protección de los derechos humanos, por encima de las leyes de amnistía, está soportada, precisamente, sobre principios de derecho internacional reconocidos con el calificativo de normas de jus cogens. Así, vale destacar en este estudio: la prohibición de amnistiar graves violaciones a los derechos humanos e infracciones al derecho internacional humanitario por ser constitutivas de crímenes internacionales; y a su vez, la imprescriptibilidad de dichos crímenes por transgredir bienes jurídi- 
co-relevantes, mandatos imperativos y seguidos por la comunidad internacional en su conjunto, justamente en la lucha contra la impunidad.

\section{LA CORTE INTERAMERICANA DE DERECHOS HUMANOS Y EL TRIBUNAL EUROPEO DE DERECHOS HUMANOS EN RELACIÓN A LAS LEYES DE AMNISTÍA}

Debido a la constante histórica de circunstancias violatorias de derechos humanos $y$, muy específicamente, por lo acontecido durante y con posterioridad a la Segunda Guerra Mundial en Europa con las sucesivas olas de transiciones democráticas, a la par con los procesos de justicia transicional en el contexto de América Latina (Arthur, 2011, págs. 75-76), se ha dado un giro trascendental en el derecho internacional de los derechos humanos con una gama de principios y corpus iuris internacional, formando sistemas que intentan hacer exigible a los Estados una práctica común en materia protectora de derechos humanos a través de pactos, tratados y declaraciones, que no son más que el resultado de esfuerzos por hacer cumplir unas pautas jurídicas mínimas comúnmente aceptadas internacionalmente.

Todo lo anterior, conforme al clamor de la humanidad por entrar en una etapa de humanización, con el propósito más amplio como expresa Faúndez (2004), de preservar y fortalecer los derechos del individuo. Con esta intención han surgido órganos, organizaciones y tribunales internacionales especializados en materia de derechos humanos, que pretenden, inter alias, sancionar internacionalmente a los Estados en supuestos de violaciones a derechos humanos, máxime si aquellas transgresiones surgen en el contexto de afectación a bienes jurídicos supranacionales (Olle Sesé, 2008, pág. 143), como ocurre en el evento de la comisión de crímenes internacionales.

Bajo esta coyuntura han surgido sistemas de protección de derechos humanos a nivel regional, que para el caso sub examine serán abordados primordialmente: el Sistema Interamericano y el Sistema Europeo de Derechos Humanos (García de Enterría, 1983), cuyos órganos juzgadores son la Corte IDH, amparada en la Convención Americana sobre Derechos Humanos o Pacto de San José de Costa Rica, de 1969, (en adelante, Convención Americana); y el TEDH, que tiene como columna vertebral el Convenio Europeo para la Protección de los Derechos Humanos y de las Libertades Fundamentales, adoptado por el Consejo de Europa en 1950, también conocido como Convenio Europeo de Derechos Humanos (CEDH). La Corte IDH y el TEDH son, por consiguiente, las máximas instancias encargadas de sancionar a los Estados partes en los convenios internacionales que nutren su respectivo sistema regional, por las violaciones a los derechos humanos en ellos consagrados.

En términos generales ambos sistemas establecen reglas específicas en relación con el objeto y fin de sus tratados, relacionadas todas ellas con el principio pacta sunt servanda de la Convención de Viena sobre el Derecho de los Tratados de 1969 (en adelante, Convención de 
Viena), que estipula como regla básica que los tratados son para cumplirse. Por ello, tanto el CEDH como la Convención Americana desarrollan la fórmula general de la obligación de respetar los derechos humanos en ellos estipulados.

En el caso concreto, la Corte IDH ha establecido como línea a seguir en sus pronunciamientos que la fórmula del artículo 1.1 de la Convención Americana será siempre:

Fundamental para determinar si una violación de los derechos humanos reconocidos por la Convención puede ser atribuida a un Estado Parte. En efecto, dicho artículo pone a cargo de los Estados Partes los deberes fundamentales de respeto y de garantía, de tal modo que todo menoscabo a los derechos humanos reconocidos en la Convención que pueda ser atribuido, según las reglas del Derecho internacional, a la acción u omisión de cualquier autoridad pública, constituye un hecho imputable al Estado (Velásquez Rodríguez vs. Honduras, 1988, párr. 164).

Esto es menester precisarlo porque los Estados no pueden excusarse en las disposiciones de su derecho interno (véase "La Última tentación de Cristo" v. Chile, 2001, pág. 17), con normas incompatibles con los tratados sobre derechos humanos por ellos ratificados; precisamente, tienen la obligación de armonizar todas las medidas legales y procedimentales existentes con los preceptos de dichos tratados y, de no existir, deben crearlas, suprimiendo como lo ha establecido la Corte IDH en reiteradas oportunidades, “las normas y prácticas de cualquier naturaleza que impliquen una violación a las garantías previstas en la Convención Americana" (CastiIlo Petruzzi y otros, vs. Perú, 2000, párr. 207; Durand y Ugarte vs. Perú, 2000, párr. 137). De lo contrario, aquellas serían de facto violatorias del mismo, análisis extensivo conforme al artículo 27 de la Convención de Viena. ${ }^{1}$

Por otro lado, aunque el CEDH no contempla como la Convención Americana (art. 2) un articulado que obligue a los Estados de manera implícita a adoptar disposiciones de derecho interno, dicho análisis no exonera el cumplimiento de normas que ostentan el carácter de imperativas como ocurre con las normas de jus cogens. Además, en el derecho de gentes:

Una norma consuetudinaria prescribe que un Estado que ha celebrado un convenio internacional, debe introducir en su derecho interno las modificaciones necesarias para asegurar la ejecución de las obligaciones asumidas. Esta norma aparece como válida universalmente y ha sido calificada por la jurisprudencia como un principio evidente (Durand y Ugarte vs. Perú, 2000, párr. 136; Garrido y Baigorria vs. Argentina, 1998, párr. 68).

Lo anterior es preciso analizarlo, dado que aun en la época actual hay Estados que contemplan leyes contrarias a la protección de los derechos humanos, a propósito de las leyes de amnistía (Forcada, 2011, pág. 92). Dichas leyes, según el consenso establecido a nivel internacional, son instrumentos que perpetúan la impunidad; esa es la postura seguida por la Corte IDH (cfr. Osorio Rivera y Familiares v. Perú, 2013; Barrios Altos

1 Reza así: "Una parte no podrá invocar las disposiciones de su derecho interno como justificación del incumplimiento de un tratado". 
v. Perú, 2001). Vale decir que en el sistema europeo de protección de los derechos humanos tanto el TEDH en algunos eventos, e incluso la Comisión Europea de Derechos Humanos, durante su funcionamiento (cfr. Dujardin contra Francia, 1991) - se han apartado de esta línea dejando algunas dudas al respecto, pues el TEDH, en el caso Marguš vs. Croacia (2014), ${ }^{2}$ aunque en su argumentación sobre las leyes de amnistía atiende desde su párrafo 126 la postura seguida por la Corte IDH , a pesar de ser contrarias a las obligaciones contenidas en los artículos 2 y 3 del CEDH, en relación con el asesinato y maltrato de civiles plantea a su vez la posibilidad de la permisividad de las leyes de amnistía, aunque es sabido el consenso internacional sobre "que aquellas eliminan la medida tal vez más efectiva para poner en vigencia el enjuiciamiento y castigos de los autores de graves violaciones de derechos humanos" (Cfr. Las Hojas vs. El Salvador, Informe n. ${ }^{\circ}$ 26/92).

\section{A. Incompatibilidad de las leyes de amnistía con la efectiva protección de los derechos humanos}

Las leyes de amnistía suelen configurarse como disposiciones de carácter general que tienen como consecuencia la extinción de la acción penal y las sanciones que ya hubieren sido im-

2 Case of Marguš v. Croatia, (Application no. 4455/19), Eur. Court HR. Judgment, (27 May 2014). párr. 126 y ss. Especialmente dice: "El Tribunal ya ha declarado que, cuando un agente del Estado ha sido acusado de crímenes de tortura o malos tratos, es de gran importancia que las actuaciones penales y la condena no hayan prescrito y que la concesión de una amnistía o indulto no deba ser permisible (ver Abdülsamet Yaman v. Turquía, n. ${ }^{\circ} 32446 / 96, \S 55,2$ de noviembre de 2004; Okkalı v. Turquía, n. ${ }^{\circ} 52067 / 99$, § 76, 17 de octubre de 2006; y Yeşil y Sevim v. Turquía, n. ${ }^{\circ} 34738 / 04, \S 38,5$ de junio de 2007). párr. 126". [Traducción no oficial]. puestas (Corcuera, 1999, pág. 28). Dicho de otro modo, consiste en borrar de la memoria legal algún aspecto de la conducta delictiva de un delincuente, al punto que en algunos contextos han surgido como producto de regímenes dictatoriales, para perpetuar los crímenes cometidos silenciando el clamor de las víctimas. Pero también vale aclarar que las amnistías podrán concederse por diversos medios, y no necesariamente toman la forma de una decisión judicial. ${ }^{3}$ Vistas así, no es erróneo afirmar que salvo casos excepcionales comprobados a través de la historia, a propósito del caso sudafricano (Elster, 2006, pág. 91; Rivas, 2013, pág. 53), las leyes de amnistía buscan poner fin al pasado, a actuaciones futuras y a las condenas pronunciadas en relación con los delitos cometidos. De hecho, han sido aceptadas las denominadas amnistías excepcionales (Corcuera, 1999, págs. 28-32), cuando a pesar del aparente "mal" que producen al absolver a violadores de derechos humanos se consideran "necesarias" para crear condiciones propicias para el logro de un acuerdo de paz o, una vez logrado este, para favorecer la reconciliación nacional.

En consecuencia, una amnistía puede aplicarse en dos situaciones: bien inmediatamente después de cometerse un delito, en cuyo caso se pone fin al procedimiento, o bien después de la condena de la persona (Marguš v. Croatia,

3 An amnesty consists in erasing from legal memory some aspect of criminal conduct by an offender. It may be granted by various means, not always taking the form of a judicial decision. Hence, such a measure does not necessarily presuppose the holding of a trial in the course of which evidence is produced for and against the accused and an assessment of his or her guilt is made. Cfr. Eur. Ct. H. R. (2014): Case of Marguš v. Croatia, pág. 60. 
2014, pág. 60). Sin embargo, aquellas serán en sí mismas violatorias de derechos humanos si se distancian de criterios de justicia, caso en el cual la postura aquí defendida asume que son per se contrarias a la tutela efectiva de los derechos humanos. Razones que han sido ampliamente argumentadas por órganos y tribunales internacionales en diversas coyunturas, como se explicará a continuación.

\section{B. Impunidad en ausencia de justicia por las leyes de amnistía}

Tanto la jurisprudencia de la Corte IDH como la línea desarrollada por el TEDH (Papon vs. Francia, 2002; Kolk y Kislyiy vs. Estonia, 2006), al igual que la experiencia heredada del Tribunal de Nüremberg, con todos sus defectos, y lo desarrollado en el Tribunal Penal de Rwanda (Prosecutor v. Jean Paul Akayesu, 1998) y en la extinta Yugoslavia (Prosecutor v. Anto Furundzija, 1998) en relación con crímenes graves de trascendencia internacional, aportan estudios de casos con reglas específicas sobre prohibiciones propias del derecho internacional, a saber: prohibición de amnistiar graves violaciones a los derechos humanos e infracciones al derecho internacional humanitario, constitutivas de crímenes internacionales; y a su vez, la imprescriptibilidad de crímenes internacionales.

Es más, interpretando dichas disposiciones conjuntamente dada la jerarquía de jus cogens que tiene la prohibición de tales conductas, no hay otra posibilidad conforme al derecho internacional que considerar que no hay plazo de prescripción a la obligación de investigar y juzgar a las personas responsables de estos delitos (Barrios Altos vs. Perú, 2001, párr. 41). Interpretación que pretende reafirmar -como lo ha reiterado la Corte IDH en los casos Comunidad Moiwana (2005), Hermanos Gómez Paquiyauri (2004) y Bulacio (2002)-, el effet utile de las disposiciones de los pactos en materia de derechos humanos y áreas conexas -como ocurre con el derecho internacional humanitario-, toda vez que se debe tener en cuenta el carácter especial de estos tratados y su implementación colectiva (cfr. Tribunal Constitucional v. Perú, 1999, párr. 36).

En consecuencia, cualquier ley que menoscabe tales prohibiciones convertidas en disposiciones de autoamnistía, puede decirse que, por un lado, contradicen el buen funcionamiento de las obligaciones internacionales contraídas $\mathrm{y}$, por el otro, debilitan gradual y sustancialmente una protección efectiva de los derechos humanos. Esta es la primera conclusión que puede sacarse, pues aquellas conducen a la perpetuación de la impunidad por ser contrarias a los derechos de acceso a la justicia, verdad y reparación.

Los estudios más recientes en la materia demuestran que la Corte IDH ha conocido de "catorce casos sobre leyes de amnistía en ejercicio de su jurisdicción contenciosa, lo cual representa casi un $8,13 \%$ del total de casos que ha conocido en materia de justicia penal" (Ferrer, 2014, pág. 70). ${ }^{4} \mathrm{Al}$ respecto es necesario men-

\footnotetext{
4 Siendo la más reciente en el tema, la sentencia del caso Osorio Rivera y Familiares v. Perú (2013). Por la expedición y aplicación de este tipo de leyes han sido condenados siete países: Perú (4), Guatemala (3), El Salvador (2), Chile (2), Brasil (1), Surinam (1) y Uruguay (1).
} 
cionar que aunque la Corte IDH ha seguido las reglas derivadas del derecho internacional de los derechos humanos en diversos asuntos (Almonacid Arellano y otros vs. Chile, 2006, párrs. 112-113; Barrios Altos vs. Perú, 2001, párr. 41) en relación con el criterio de prohibición de las leyes de amnistía, sobre todo si las violaciones a los derechos humanos han sido constitutivas inter alias de crímenes de lesa humanidad, ${ }^{5}$ la Convención Americana no establece una regla específica en este sentido y tampoco lo hace en el contexto europeo el CEDH.

No obstante, el problema de las amnistías ha sido considerado por la Corte IDH en diversas oportunidades de la mano de la Comisión Interamericana de Derechos Humanos, esencialmente por reclamos contra Estados partes en la Convención Americana que:

En busca de un mecanismo de pacificación y reconciliación nacional, han recurrido a estas dejando en desamparo a un sector dentro del que se hallan muchas víctimas inocentes de la violencia, las que se ven privadas del derecho a la justicia en sus justos reclamos contra quienes cometieron excesos y actos de barbarie en su contra (Garay Hermosilla y otros vs. Chile, 1997, párr. 49).

Por ello, la Corte IDH se ha valido de los principios del derecho internacional para hacer una interpretación extensiva acorde con el objeto y fin de la Convención Americana, en armonía con

5 Cfr. Inter-Am. Ct. H. R., casos: Goiburú y otros, vs. Uruguay, 2006, párr. 28; Masacre Plan de Sánchez vs. Guatemala, 2004, párr. 12; Almonacid Arellano y otros vs. Chile, 2006, párr. 99; Penal Miguel Castro Castro vs. Perú, 2006, párr. 404 y La Cantuta vs. Perú, 2006, párrs. 225-226. los estándares internacionales en la materia. En esa medida sigue la regla de la prohibición de amnistiar graves violaciones a los derechos humanos, en el entendido que a la luz de las obligaciones generales consagradas en los artículos 1.1 y 2 de la Convención Americana, los Estados tienen el deber de tomar las providencias de toda índole para que nadie sea sustraído de la protección judicial y del ejercicio del derecho a un recurso sencillo y eficaz, en los términos de los artículos 8 y 25 de la Convención.

Así, verbigratia, en el caso Barrios Altos contra Perú (2001), el primero analizado en materia de amnistía, como consecuencia de los asesinatos y lesiones resultantes del operativo "Barrios Altos" en el que fallecieron 15 personas por la intervención de fuerzas del Estado, se originaron a posteriori las leyes de amnistía n.os 26479 y 26492 como medidas que impedían la investigación, procesamiento y sanción de los responsables. La Corte IDH conforme a los artículos 1.1, 2, 8 y 25 de la Convención, dictaminó que este tipo de leyes impide la identificación de los individuos responsables de violaciones a derechos humanos, ya que se obstaculizan la investigación y el acceso a la justicia e impiden a las víctimas y a sus familiares conocer la verdad y recibir la reparación correspondiente. Definió por ello que una ley de amnistía es manifiestamente incompatible con la "letra" de esas disposiciones.

Algo similar se analizó en el caso Almonacid Arellano y otros vs. Chile (2006), ya que el Estado no podía argumentar prescripción e irretroactividad de la ley penal, ni el principio non bis in ídem, así como cualquier excluyente similar de 
responsabilidad, pues al constituirse crímenes de lesa humanidad, además de ser inamnistiables, eran imprescriptibles (párr. 152). Razón que llevó a la Corte IDH a sancionar al Estado por la denegación de justicia que sufrieron las víctimas, por el incumplimiento de los deberes generales consagrados en los artículos 1.1 y 2 de la Convención Americana, por la falta de investigación y sanción oportuna de los responsables de la ejecución extrajudicial del señor Luis Alfredo Almonacid Arellano, a partir de la aplicación del Decreto Ley n. ${ }^{\circ}$ 2.191, Ley de Amnistía adoptada en 1978 en Chile, así como por la falta de reparación adecuada a favor de sus familiares. Si no fuera así, los derechos humanos, independientemente del tratado que los contemple, estarían desprovistos de protección efectiva (Comunidad Moiwana vs. Surinam, 2005, párr. 167).

En este orden de ideas, puede afirmarse que si quien falla es el poder legislativo en su tarea de suprimir dichas leyes, aquellas serán nulas ab initio, a propósito del Decreto Ley 2.191 emitido por el gobierno de Augusto Pinochet, evento en el cual el poder judicial está vinculado al deber de garantizar los derechos establecidos en el artículo 1.1 de la Convención, y consecuentemente debe abstenerse de aplicar cualquier normativa contraria a ella (Ferrer, 2104, pág. 78). Por otra parte, en lo que respecta al Sistema Europeo de Derechos Humanos puede afirmarse que no ha seguido de manera clara la misma línea:

Así, en 1991, en el caso Dujardin contra Francia, la Comisión Europea de Derechos Humanos dio validez a una ley de amnistía aprobada en referéndum popular y posteriormente por la Asamblea Nacional francesa, con vistas a conceder la independencia a Nueva Caledonia y que se extendía a hechos que pueden calificarse como crímenes de guerra. En contra de los argumentos de los demandantes la Comisión rechazó la demanda negando que la amnistía supusiera una violación del art. 2 [que consagra el derecho a la vida]. (Gil, 2012, pág. 11).

Por otra parte, en el caso Marguš vs. Croacia (2014), como se explicará a posteriori, aunque el TEDH al tratarse de crímenes de guerra se ampara en los materiales relevantes existentes en el derecho internacional, teniendo en cuenta el amplio precedente desarrollado por la Corte IDH en la materia puede decirse que se aparta de esta línea principalmente para apuntar a que las violaciones graves de los derechos humanos y las infracciones al derecho internacional humanitario no deben terminar en amnistía, indulto o prescripción.

Como se puede advertir, la comprensión de la incongruencia de las leyes de amnistía con los derechos humanos siempre estará relacionada con el deber que tienen los Estados no solo de investigar, sino de reparar a las víctimas y sancionar al infractor, para que los hechos perpetrados no queden bajo la sombra de la impunidad (Egmez v. Chipre, 2000, párr. 71; Turan Cakir v. Bélgica, 2009, párr. 69). Es de resaltar que podrá hablarse de un estado de cosas constitutivas de impunidad cuando aquellas en sí mismas no atienden en su conjunto a una efectiva investigación, persecución, captura y enjuiciamiento de los responsables de violaciones a los derechos humanos, toda vez que los Estados 
tienen "la obligación de combatir tal situación por todos los medios legales disponibles, ya que la impunidad propicia la repetición crónica de las violaciones de derechos humanos y la total indefensión de las víctimas y de sus familiares" (Paniagua Morales y otros vs. Guatemala, 1998, párr. 173).

Sobre el particular, la Corte IDH ha destacado en su línea jurisprudencial, en los casos Velásquez Rodríguez vs. Honduras (1988), Gelman vs. Uruguay (2011), Cabrera García y Montiel Flores vs. México (2010), que la obligación estatal de investigar, sancionar y enjuiciar por las violaciones de derechos humanos adquiere particular importancia ante la gravedad de los delitos cometidos y la naturaleza de los derechos lesionados, en especial en aquellos eventos donde dicha obligación ha alcanzado el carácter de jus cogens (Goiburú y otros, v. Uruguay, 2006, párr. 84; Gomes Lund y otros, (Guerrilha do Araguaia) vs. Brasil, 2010, párr. 137), como ocurre con la prohibición de la desaparición forzada de personas y la tortura.

En específico, la obligación de investigar violaciones de derechos humanos se encuentra dentro de las medidas positivas que deben adoptar los Estados, es una obligación de medios y no de resultado, pues según lo establecido en el caso Rosendo Cantú y otra (2010):

Debe ser asumida por el Estado como un deber jurídico propio y no como una simple formalidad condenada de antemano a ser infructuosa, o como una mera gestión de intereses particulares, que dependa de la iniciativa procesal de las víctimas, de sus familiares o de la aportación privada de elementos probatorios (párr. 175).

En el caso concreto, la Corte IDH se ha pronunciado sobre la incompatibilidad de las amnistías con la Convención Americana en los eventos de graves violaciones a los derechos humanos en diferentes Estados del continente americano, a saber: Perú (Barrios Altos y La Cantuta), Chile (Almonacid Arellano y Otros), Brasil (Gomez Lund y Otros - Guerrilha do Araguaia), Guatemala (Myrna Mack Chang), inter alias, concluyendo:

Son inadmisibles las disposiciones de amnistía, las disposiciones de prescripción y el establecimiento de excluyentes de responsabilidad que pretendan impedir la investigación y sanción de los responsables de las violaciones graves de los derechos humanos tales como la tortura, las ejecuciones sumarias, extralegales o arbitrarias y las desapariciones forzadas, todas ellas prohibidas por contravenir derechos inderogables reconocidos por el Derecho Internacional de los Derechos Humanos (Barrios Altos v. Perú, sentencia de fondo, párr. 41; Almonacid Arellano y otros v. Chile, 2006, párr. 112).

Sin embargo, el TEDH deja algunas dudas al respecto en esta línea, pues en el caso Marguš vs. Croacia, en su argumentación sobre las leyes de amnistía, aunque asume que aquellas son contrarias a las obligaciones contenidas en los artículos 2 y 3 del CEDH, en relación con el asesinato y maltrato de civiles plantea a su vez la posibilidad de permisividad de dichas leyes, interpretación que se deduce cuando expresa que pueden ser viables en circunstancias particulares, como por ejemplo, en los procesos de reconciliación y/o una forma de compensación a las víctimas. 
Vale decir que en una línea jurisprudencial un poco ambigua, el TEDH en su decisión en el caso Ould Dah v. Francia (2009) en referencia al Comité de Derechos Humanos de las Naciones Unidas (1994) y al TPIY, ratificó que la amnistía es generalmente incompatible con el deber de los Estados de investigar actos como la tortura, y que la obligación de enjuiciar a los criminales no debe, por lo tanto, ser socavada por la concesión de la impunidad para el agresor en la forma de una ley de amnistía que podría considerarse contraria al derecho internacional. El Tribunal es de la opinión que el mismo análisis aplica para los crímenes de guerra.

No obstante, más bien recientemente, en el caso de España, y sin pronunciarse en absoluto sobre la Ley de Amnistía 46/1977 -que tiene efectos de olvido de los crímenes y violaciones de derechos humanos ocurridos en España durante la época del franquismo, además de interponerse para el ejercicio de la tutela judicial efectiva- el TEDH en el caso Gutiérrez Dorado y Dorado Ortiz, en marzo de 2012, considera que la demanda debe ser rechazada por extemporánea, debido al excesivo e injustificado retraso por parte de los demandantes una vez que han tenido o debido tener conocimiento de que no se había iniciado una investigación; circunstancia en la que podría ser previsible que no se llevaría a cabo una investigación eficaz en el futuro (párr. 39).

El Tribunal se basó en la sentencia del caso Varnava y otros vs. Turquía, (2009, párrs. 165-166), contexto en el que se valoró la desaparición forzada de varias personas por una operación del ejército turco en el norte de Chipre, en 1974, para concluir que a finales de 1990 debió considerarse evidente que los mecanismos establecidos para investigar las desapariciones en Chipre no ofrecían ya ninguna esperanza realista de que fueran a progresar en un futuro cercano, tanto en cuanto a la localización de los cuerpos como en relación con la determinación del paradero de las personas desaparecidas.

En suma, el argumento central en el caso Gutiérrez Dorado y Dorado Ortiz vs. España, es que en casos de desaparición forzada los demandantes no pueden esperar indefinidamente antes de acudir al TEDH, pues son las presuntas víctimas las que deben activar el aparato judicial, demostrando a su vez diligencia y cuidado en sus requerimientos. De hecho, en opinión del TEDH:

Con el paso del tiempo la memoria de los testigos se desvanece, los testigos pueden morir o ser ilocalizables, las pruebas se deterioran o pierden, y las perspectivas de que pueda ser emprendida cualquier investigación eficaz disminuye cada vez más (párr. 37).

Argumento que en mi concepto es bastante débil, dado que el fondo del asunto debe ir más allá de la extemporaneidad de la demanda. Si bien se acudió a diversas instancias con un resultado ineficaz torpedeado también por la vigencia de la Ley de Amnistía española, el 27 de marzo de 2012 el TEDH declaró inadmisible la demanda, a pesar de la existencia del principio general de derecho internacional contemporáneo aut dedere aut judicare, cuya máxima apunta a que el Estado español debería juzgar a los presuntos criminales o extraditarlos; medida que 
encausaría a su vez el derecho a la verdad del que son titulares las víctimas del franquismo, toda vez que actualmente aún permanece vivo el activismo que quiere reivindicar el derecho a la justicia (De Domingo, 2012, págs. 11-12).

Conjuntamente, se trata de una sentencia guiada por un movimiento de víctimas que no ha tenido ningún tipo de amparo ni respuesta efectiva en relación con la desaparición forzada de personas durante la Guerra Civil española. En el caso puntual, se debatió sobre la desaparición forzada del parlamentario Luis Dorado Luque perteneciente al Partido Socialista Obrero Español (PSOE)-, desde el 28 de julio de 1936 hasta la fecha y, por otra parte, sobre el efecto de la Ley de Amnistía para garantizar la extinción de la responsabilidad penal a toda persona que hubiera cometido cualquier delito por razones políticas antes del 15 de diciembre de 1976. Este último aspecto pasó desapercibido en el análisis hecho por el TEDH, empero, el debate lo centró en su competencia en razón al tiempo, aunque se ha dicho hasta el cansancio que los crímenes internacionales no prescriben, y que la desaparición forzada de personas es un delito continuado, tesis seguida por la Corte $\mathrm{IDH}^{6}$ y por el TEDH (a la luz de Varnava y Otros, 2009, párr. 148), pero no valorada en este caso. En suma, el TEDH inadmite la demanda argumentando la tesis de que debió haber sido evidente para los demandantes la inexistencia de una esperanza realista de que en un futuro cercano progresara

6 Cfr. Inter-Am. Ct. H. R., casos: Trujillo Oroza vs. Bolivia, 2002, párr. 21; Genie Lacayo vs. Guatemala, 1995, párr. 25; Blake vs. Guatemala, 2008, párr. 7. tanto la localización del cuerpo como la determinación de la suerte del desaparecido.

Igualmente, el TEDH resaltó el que el derecho de demanda individual es aplicable a España desde el 1 de julio de 1981 y la demanda no fue presentada sino hasta el 1 de junio de 2009 , es decir, casi 28 años después de dicha fecha, y 63 años después de la desaparición. Sin embargo, en relación con los crímenes ocurridos en el franquismo y por los efectos de la Ley de Amnistía como instrumento de impunidad, en el caso sub examine, el Grupo de Trabajo sobre las Desapariciones Forzadas o Involuntarias de la ONU, en sus observaciones preliminares, al concluir su visita a España manifestó:

La desaparición forzada es un delito continuado y una vulneración permanente de los derechos humanos mientras no se hayan esclarecido la suerte y el paradero de las víctimas. (...) Adicionalmente, [en España] no se ha tenido en cuenta que el carácter de delito de lesa humanidad de las desapariciones cometidas durante la Guerra Civil y la dictadura. (...) El Grupo de Trabajo insta al Estado español a juzgar las desapariciones forzadas a la luz de estas obligaciones internacionales y a establecer legislativamente la imprescriptibilidad de las desapariciones forzadas o la determinación de que la prescripción solo puede comenzar a computarse a partir del cese de la desaparición forzada (2013).

En este orden de ideas, como concluye Gil (2012), el TEDH parece haber resuelto el tema de las víctimas de la Guerra Civil y del franquismo de la forma más cómoda para él, evitando pronunciarse sobre las cuestiones jurídicas más 
peliagudas y discutidas, cuestiones que a pesar de su ambigüedad ya han sido desarrolladas por su jurisprudencia en otras oportunidades. Lo grave del asunto es que al centrarse solo en el rechazo de la demanda en "todos sus puntos por extemporaneidad, con el argumento de que los demandantes pudieron acudir al tribunal desde 1981, cierra las puertas a todas las víctimas, incluidas las de las últimas etapas del franquismo" (Gil, 2012, pág. 23).

Sin embargo, en el caso español todavía las víctimas del franquismo reclaman el derecho a la verdad, ligado a la reconstrucción de la memoria histórica como forma de reparación, derechos todos ellos constitutivos de la justicia, idea que también soporta la existencia de la Ley 52 de 2007 que puntualmente contempla el derecho a la memoria personal y familiar de cada ciudadano (Bonet y Alija, 2009, pág. 44), dado lo acontecido durante la Guerra Civil y la dictadura. Pese a esto, el TEDH elude pronunciarse en un tema tan polémico, sin aportar nada al clamor de las víctimas en relación con la ley de amnistía.

En otro análisis, su homónima, en el caso Masacres de El Mozote v. El Salvador (2012), estableció que la posibilidad de conceder amnistías como una medida para procurar el cese internacional y posibilitar el retorno a la paz, prevista por el artículo 6.5 del Protocolo II adicional de las Convenciones de Ginebra, no puede incluir todo tipo de crímenes, puesto que el derecho internacional humanitario establece la obligación de investigar y juzgar crímenes de guerra. En consecuencia, las leyes de amnistía solo pue- den aplicarse a hechos que no caben en la categoría de crímenes de guerra o crímenes contra la humanidad. Ciertamente, el caso español seguirá siendo un ejemplo de dudosa impunidad en razón de las leyes de amnistía y, en esto, el TEDH parece no querer pronunciarse.

\section{ESTÁNDARES INTERNACIONALES SOBRE LAS LEYES DE AMNISTÍA}

Tanto el Comité de Derechos Humanos de Naciones Unidas como la Corte IDH y la Comisión Interamericana de Derechos Humanos, y en general los órganos internacionales en materia protectora de derechos humanos en los diferentes sistemas de protección, han exigido la eliminación de leyes de amnistía por cuanto aquellas no conducen al esclarecimiento de la verdad, al derecho a la justicia y al derecho a obtener una justa reparación; en otros contextos, como lo ha explicado el Sr. Max van der Stoel, Relator Especial de la Comisión de Derechos Humanos, las denominadas leyes de amnistía inspiran poca confianza, o ni siquiera en sí mismas son leyes de amnistía (onu, 1995, párr. 7).

Por su parte, el Comité de los Derechos Humanos de las Naciones Unidas en su Observación general n. ${ }^{\circ} 20$, núm. 15 , del $44^{\circ}$ periodo de sesiones (1992), sobre el artículo 7 del Pacto Internacional expresó haber notado que algunos Estados habían concedido la amnistía por actos de tortura, y precisó:

Las amnistías son generalmente incompatibles con la obligación de los Estados de investigar tales actos, de garantizar la protección contra 
dichos actos en su jurisdicción; y de velar por que no se reproduzcan en el futuro. Los Estados no pueden privar a los particulares del derecho a un recurso útil incluido el derecho a una indemnización y a la reparación más completa posible.

Como se advirtió en el caso Gelman vs. Uruguay (2011), las disposiciones de amnistías o figuras análogas han sido uno de los obstáculos alegados por algunos Estados para investigar y, en su caso, sancionar a los responsables de violaciones graves a los derechos humanos (párr. 195); en esa medida diversos instrumentos internacionales han tipificado y consagrado el deber de investigar y sancionar actos constitutivos de crímenes internacionales, entre ellos: los Convenios de Ginebra de 1949, la Convención contra la Tortura y Otros Tratos o Penas Crueles Inhumanas o Degradantes (1984), la Convención sobre la Imprescriptibilidad de los Crímenes de Guerra y de los Crímenes contra la Humanidad (1968), la Convención para la Prevención y Sanción al Crimen de Genocidio (1948), la Convención Interamericana para Prevenir y Sancionar la Tortura (1986), el Estatuto de Roma por el cual se crea la Corte Penal Internacional (1998) y el Convenio del Consejo de Europa sobre la Lucha contra la Trata de Seres Humanos (2005), entre otros.

Sobre esta base, en el informe El Estado de derecho y la justicia de transición en las sociedades que sufren o han sufrido conflictos (onu, 2004, párr. 10), el secretario general de las Naciones Unidas señaló: “Los acuerdos de paz aprobados por las Naciones Unidas nunca pueden prome- ter amnistías por crímenes de genocidio, de guerra, o de lesa humanidad o infracciones graves de los derechos humanos".

En el mismo sentido, la Comisión de las Naciones Unidas sobre Derechos Humanos, en sus resoluciones 2002/79 (abril 25 de 2002), 2003/72 (25 de abril 2003) y 2004/72 (21 de abril de 2004) ha establecido, entre otras cosas, que las amnistías no se concederán a aquellos que cometen violaciones de los derechos humanos e infracciones al derecho internacional humanitario. Por tanto acoge con satisfacción la supresión o la anulación de la amnistía y de otras clases de inmunidad o la renuncia a ellas, y reconoce también la constatación del secretario general de que los acuerdos de paz aprobados por las Naciones Unidas nunca pueden prometer amnistías por crímenes de genocidio, crímenes contra la humanidad, crímenes de guerra o violaciones graves de los derechos humanos.

Más recientemente, el Comité de Derechos Humanos de la onu con ocasión del sexto informe ordinario presentado por Chile, en julio de 2014, ha solicitado al Estado de Chile que derogue el Decreto Ley de Amnistía n. 2191 del 19 de abril de 1978, impuesto durante el régimen del general Pinochet con el objetivo de "garantizar la impunidad a los autores de las violaciones de los derechos humanos cometidas durante su régimen, entre 1973 y 1990" (Comisión Interamericana de Derechos Humanos, 1996), dado que los actos perpetrados por los agentes de la dictadura militar hoy por hoy constituyen crímenes de lesa humanidad. 


\section{REFLEXIONES FINALES}

Por todo lo expuesto, estas decisiones coincidentes con el criterio de diversos órganos y tribunales internacionales de derechos humanos permiten concluir de manera uniforme que tanto las leyes de amnistía como las medidas legislativas comparables que impiden o dan por terminada la investigación y juzgamiento, ${ }^{7}$ independientemente de que se trate de agentes de un Estado, cuando puedan ser responsables de serias violaciones de derechos humanos, violan múltiples disposiciones de instrumentos internacionales.

Por lo que el consenso generalmente aceptado apunta a declarar nulas de manera absoluta, por contravenir derechos inderogables reconocidos por el derecho internacional de los derechos humanos, "las disposiciones de amnistía, de prescripción, los indultos y el establecimiento de cualquier tipo de excluyentes de responsabilidad, que pretendan impedir la investigación, procesamiento y sanción de los responsables de este tipo de crímenes" (Sánchez, 2010, pág. 23). Por otra parte, no puede pensarse en su permisibilidad en contextos donde la constante ha sido la violación generalizada y sistemática de derechos humanos, incluso si el debate está guiado por procesos de paz o reconciliación. Esto no puede pasarse por alto, puesto que significaría debilitar la idea de protección de los

7 Cfr. Caso Gelman vs. Uruguay, párr. 197. Inter-Am. Comm'n HR. (2000): Informe No. 44/00, Caso 10.820. (Perú), párr. 68; Inter-Am. Comm'n HR. Informe No. 47/00, Caso 10.908. (Perú), párr. 76. En el mismo sentido, cfr. Inter-Am. Comm'n HR. (1999): Informe No. 55/99, casos $10.815 ; 10.905 ; 10.981 ; 10.995 ; 11.042$ y 11.136 vs. Perú, párr. 140. derechos humanos, amén de fortalecer y darle sentido "vivo" a estos, procurando a su vez la tan anhelada garantía de no repetición de actos de barbarie.

\section{Referencias}

1. Almonacid Arellano y otros vs. Chile. InterAm. Ct. H. R. (Excepciones Preliminares, Fondo, Reparaciones y Costas), Serie C No. 154 (2006).

2. Andreu-Guzmán, F. (2012). Retroactividad penal de crímenes internacionales. Bogotá: Comisión Colombiana de Juristas.

3. Arthur, P. (2011). Cómo las transiciones reconfiguraron los derechos humanos: una historia conceptual de la justicia transicional. En F. Reátegui (Coord.), Justicia transicional. Manual para América Latina (págs. 73-134). Brasilia: Comisión de Amnistía.

4. Barrios Altos vs. Perú. Inter-Am. Ct. H. R. (Fondo), Serie C. No. 75 (2001).

5. Blake vs. Guatemala. Inter-Am. Ct. H. R. (Fondo). Voto razonado del juez A. A. Cançado Trindade, Serie C, No. 36 (1998).

6. Bonet Pérez, J. y Alija Fernández, R. (2009). Cuadernos Deusto de derechos humanos. Impunidad, derechos humanos y justicia transicional. Bilbao: Universidad de Deusto.

7. Bulacio vs. Argentina. Inter-Am. Ct. H. R. (Fondo, Reparaciones y Costas), Serie C. No. 100 (2002). 
8. Caso 10.820 vs. Perú. Inter-Am. Comm'n H. R. Informe No. 44/00 (2000).

9. Caso 10.908 vs. Perú. Inter-Am. Comm'n H. R. Informe No. 47/00 (2000).

10. Casos 11.228, 11.229, 11.231 y 11282 vs. Chile. Inter-Am. Comm'n H. R. Informe No. 34/96 (1996).

11. Casos 11.228, 11.229, 11.231 y 11282 vs. Chile. Informe No. 55/99 (1996).

12. Casos 10.815; 10.905; 10.981; 10.995; 11.042 y 11.136 vs. Perú. Inter-Am. Comm'n H. R. Informe No. 55/99 (1999).

13. Castillo Petruzzi y otros, vs. Perú. Inter-Am. Ct. H. R. (Fondo, Reparaciones y Costas), Serie C No. 52 (1999).

14. Comisión Interamericana de Derechos Humanos. (1996). Informe n. ${ }^{\circ}$ 34/96. Casos $11.228,11.231$ y 11.282 vs. Chile. Recuperado de: https://www.cidh.oas.org/ annualrep/96span/Chile11228.htm

15. Comunidad Moiwana vs. Suriname. InterAm. Ct. H. R. (Excepciones Preliminares, Fondo, Reparaciones y Costas, ) Serie C. No. 124 (2005).

16. Corcuera Cabezut, S. (1999). Las leyes de amnistía en el derecho internacional de los derechos humanos. Anuario del Departamento de Derecho de la Universidad Iberoamericana, 29, 23-38.
17. De Domingo, T. (2012). Justicia transicional, memoria histórica y crisis nacional. Navarra: Aranzadi.

18. Durand y Ugarte vs. Perú. Inter-Am. Ct. H. R. (Fondo), Serie C No. 68 (2000).

19. Egmez vs. Chipre. Eur. Ct. H.R. Fourth Section No. 30873/96 (2000).

20. Elster, J. (2006). Rendición de cuentas. La justicia transicional en perspectiva histórica. Buenos Aires: Katz.

21. Faúndez Ledesma, H. (2004). El sistema interamericano de protección de los derechos humanos: aspectos institucionales y procesales. San José: Instituto Interamericano de Derechos Humanos.

22. Ferrer Mac-Gregor. E. (2014). Las siete principales líneas jurisprudenciales de la Corte Interamericana de Derechos Humanos aplicables a la justicia penal. Revista IIDH, 59, 29-117.

23. Forcada Barona, I. (2011). Derecho internacional y justicia transicional. Cuando el derecho se convierte en religión. Navarra: Civitas.

24. Garay Hermosilla y otros vs. Chile. Inter-Am. Ct. H. R. Caso 10.843. Informe No. 36/96, OEA/Ser.L/V/II.95 Doc. 7 rev.156 (1997).

25. García de Enterría, E. (1983). El sistema europeo de derechos humanos. Madrid: Civitas. 
26. Garrido y Baigorria vs. Argentina. Inter-Am. Ct. H. R. (Reparaciones), Serie C No. 39 (1998).

27. Gelman vs. Uruguay. Inter-Am. Ct. H. R. (Fondo y Reparaciones), Serie C No. 221 (2011).

28. Genie Lacayo vs. Nicaragua. Inter-Am. Ct. H. R. (excepciones preliminares), Serie. C No. 21 (1995).

29. Gil Gil, A. (2012). Los crímenes de la guerra civil española: ¿Responsabilidad del Estado Español por infracción del Convenio Europeo de Derechos Humanos? Revista para el Análisis del Derecho, 4, 1-29.

30. Goiburú y otros, vs. Uruguay. Inter-Am. Ct. H. R. (Fondo, Reparaciones y Costas), Serie C No. 153 (2006).

31. Gomes Lund y otros (Guerrilha do Araguaia), vs. Brasil. Inter-Am. Ct. H. R. (Excepciones Preliminares, Fondo, Reparaciones y Costas), Serie C No. 219 (2010).

32. Gutiérrez Dorado y Dorado Ortiz, vs. España. Eur. Court HR. Tercera Sección No. 30141/09 (marzo 12 de 2012).

33. Hermanos Gómez Paquiyauri vs. Perú. InterAm. Ct. H. R. (Fondo, Reparaciones y Costas), Serie C. No. 110 (2004).

34. Instituto Nacional de Derechos Humanos. (2014). Informe anual situación de los derechos humanos en Chile. Recuperado de: http://www.indh.cl/informe-anual-si- tuacion-de-los-derechos-humanos-en-chile-2014.

35. Inter-Am. Comm'n H. R. (1994): Informe sobre la situación de los derechos humanos en el Salvador, OEA/Ser.L/II.85 Doc. 28.

36. Kolk y Kislyiy vs. Estonia. Eur. Court HR. Fourth Section (Admissibility). No. 23052/04 y No. 24018/04 (2006).

37. "La Última tentación de Cristo" (Olmedo Bustos y otros) vs. Chile. Inter-Am. Ct. H. R. (Fondo, Reparaciones y Costas), Serie C No. 73 (2001).

38. Las Hojas vs. El Salvador. Inter-Am. Ct. H. R. Caso 10.287. Informe No. 26/92, OEA/ Ser.L/V/II.83 Doc (1993).

39. Laurence Dujardin y otros c. Francia. Eur. Comm'n H. R. (Admissibility). No. 16734/90 (1991).

40. Marguš vs. Croatia. Eur. Court HR First Section No. 4455/10 (2012).

41. Marguš vs. Croatia. Eur. Ct. H.R. Grand Chamber No. 4455/10 (2014).

42. Masacre Plan de Sánchez vs. Guatemala. Inter-Am. Ct. H. R. (Fondo). Voto razonado del juez Cançado Trindade, Serie C No. 105 (2004).

Masacres de El Mozote y lugares aledaños vs. El Salvador. Inter-Am. Ct. H. R (Fondo, Reparaciones y Costas) Serie C No. 252 (2012). 
43. Naciones Unidas. (1995). Informe sobre la situación de los derechos humanos en Iraq. A/50/734.

44. Naciones Unidas. (2004). Informe del Secretario General al Consejo de Seguridad de Naciones Unidas. El Estado de derecho y la justicia de transición en las sociedades que sufren o han sufrido conflictos. Doc. s/2004/616.

45. Naciones Unidas. (30 de septiembre de 2013). Observaciones preliminares del Grupo de Trabajo sobre las Desapariciones Forzadas o Involuntarias de la ONU al concluir la vista a España. Madrid: Autor.

46. Office of the High Commissioner for Human Rights [OHCHR], (1992). Observación General n. ${ }^{\circ}$ 20. Comentarios generales adoptados por el Comité de los Derechos Humanos, artículo 7 - Prohibición de la tortura u otros tratos o penas crueles, inhumanos o degradantes, $44^{\circ}$ período de sesiones. Doc. HRI/GEN/1/Rev.7 at 173.

47. Olle Sesé, M. (2008). Justicia universal para crímenes internacionales. Madrid: La Ley.

48. Osorio Rivera y Familiares vs. Perú. Inter-Am. Ct. H. R. (Excepciones Preliminares, Fondo, Reparaciones y Costas), Serie C No. 274 (2013).

49. Ould Dah v. France. Eur. Court HR (Admissibility), No. 13113/03 (2009).
50. Paniagua Morales y otros vs. Guatemala. Inter-Am. Ct. H. R. (Fondo), Serie C, No. 37 (1998).

51. Papon vs. Francia. Eur. Court HR. First Section No. 54210/00 (2002).

52. Penal Miguel Castro Castro vs. Perú. InterAm. Ct. H. R. (Fondo, Reparaciones y Costas), Serie C No. 160 (2006).

53. Prosecutor vs. Anto Furundzija. ICTY No. IT95-17/1-T, párrs. 153-154 (1998).

54. Prosecutor vs. Jean Paul Akayesu. TPIR (Judgment), Trial Chamber, Case No. 96-4 (1998).

55. Rivas, P. (2013). Salir de la oscuridad. Perdón, derecho y política en los procesos de justicia transicional. Navarra: Aranzadi.

56. Rosendo Cantú y otra vs. México. Inter-Am. Ct. H. R. (Excepción Preliminar, Fondo, Reparaciones y Costas), Serie C No. 216 (2010).

57. Sánchez, J. (2010). Corte Interamericana, crímenes contra la humanidad y construcción de la paz en Suramérica, Barcelona: Institut Català Internacional per la Pau.

58. Tribunal Constitucional vs. Perú. Inter-Am. Ct. H. R. Competencia, Serie C. No 55 (1999).

59. Trujillo Oroza vs. Bolivia. Inter-Am. Ct. H. R. (Reparaciones y Costas), Serie C No. 92 (2002). 
60. Turan Cakir vs. Bélgica. Eur. Court HR. Second Section No. 44256/06 (2009).

61. Varnava and Others vs. Turkey. Eur. 62. Velásquez Rodríguez vs. Honduras. InterCt. H. R. Grand Chamber (Applications nos. 16064/90, 16065/90, 160/66/
$90,160 / 68 / 90,16069 / 90,16070 / 90$, $16071 / 90,16072 / 90$ y $16073 / 90$ (2009).

Am. Ct. H. R. (Fondo), Serie C No. 4 (1988). 